\title{
Unexpected improvement after prolonged posttraumatic vegetative state
}

\author{
WFM ARTS, ${ }^{*}$ HR VAN DONGEN,${ }^{*}$ J VAN HOF-VAN DUIN,$\dagger$ E LAMMENS $\ddagger$ \\ From the Departments of Neurology* and Physiology I, $\dagger$ University Hospital and Medical Faculty, Erasmus \\ University, and the Humanitas Clinics, $\ddagger$ Rotterdam, the Netherlands
}

SUMMARY An 18-year-old girl suffered a severe head injury in a traffic accident. As a result, she was vegetative for about $2 \frac{1}{2}$ years. She then showed signs of a gradually returning responsiveness. Six years after the accident, she is now able to comprehend and communicate, shows considerable interest in her surroundings and is able to establish interpersonal relationships. Moreover, the improvement is still continuing. Her severe contractures, however, prevent her from making full use of these regained mental capacities. Such a mental recovery after such a long-lasting vegetative state of traumatic origin has not previously been described.

Great moral and economic dilemmas have to be faced in the care of severely brain damaged patients. ${ }^{1}$ Therefore, attempts have been made to develop criteria predicting the outcome of coma, immediately and during the first week after its onset. ${ }^{2-5}$ Other authors have investigated the prognosis of patients who are in a vegetative state. ${ }^{6-9}$ Former studies have defined statistical probabilities to predict the outcome in individual patients and generally indicate a gloomy prognosis for patients who are in a persistent vegetative state. However, unexpected recovery may occur..$^{910}$ We here report a patient with a return of meaningful mental capacities after a long-lasting vegetative state of traumatic origin. Detailed neuropsychological and neuro-ophthalmological findings are presented.

\section{Case report}

In August 1978, an 18-year-old girl with a normal history and of average intelligence was hit by a car. She was immediately comatose (Glasgow Coma Scale: E1, M3, V1) with abnormal flexion movements of both arms and a tonic extension posture of both legs. The pupils were equal and reacting, the ocular movements were conjugate and full,

Address for reprint requests: Dr WFM Arts, University Hospital Dijkzigt, 40 Dr. Molewaterplein, 3015 GD Rotterdam, The Netherlands.

Received 15 January 1985 and in revised form 26 April 1985 Accepted 10 May 1985 and the corneal reflexes were present. The head and eyes were deviated to the left. The initial CT scan showed subarachnoid blood and compression of the basal cisterns and ventricles. She was hyperventilated to a $\mathrm{pCO}_{2}$ of $30 \mathrm{~mm}$ $\mathrm{Hg}$ for about 24 hours, and then was able to breathe independently. A repeat neurological examination was essentially identical, with the exception of the ocular motility: the visual axes diverged, and there were no spontaneous ocular movements. However, the oculocephalic reflexes were intact. A repeat CT scan showed bilateral frontal contusions, but no intracerebral accumulation of blood.

After two weeks, she sometimes opened her eyes spontaneously. The eye movements were again conjugate, but ocular fixation or pursuit movements were never seen. The flexor posturing of the arms and the extensor posturing of the legs persisted, and despite vigorous therapy severe contractures of all extremity joints developed, complicated by para-articular calcifications. There were no signs of recognition or communication. Her neurological state did not improve, and after five months she was taken into residential care, with a diagnosis of a vegetative state.

Twelve and sixteen months after the accident, there were no signs of a self-conscious existence, and contact with her was impossible. She turned her head in reaction to visual and auditory stimuli. Roving eye movements were noted. Painful stimuli caused grimacing, tachypnoea and tachycardia. The situation remained unchanged until about $2 \frac{1}{2}$ years after the accident, when she became able to lift her left leg and to nod. At $3 \frac{1}{2}$ years she started to react to visitors. She could not vocalise. Her menstrual cycle returned, and she became able to indicate the need to void. Subsequently, a gradual improvement in her mental functions was observed. Five years after the accident, she was alert and showed an active interest in her surroundings. 
She recognised familiar persons and her personal belongings. There was an exaggerated emotional lability. From 5 to 6 years after the accident, extensive examinations were performed.

Neurological examination She was conscious and cooperative, but the motility of the extremities was virtually nil because of the severe contractures. Therefore, the strength in the extremities could only be tested in the quadriceps femoris and the hamstrings, in which a normal and symmetrical strength was found, but with hypertonia. The right elbow could move over about $30^{\circ}$; flexion was normal, extension weak. The deep tendon reflexes were symmetrical and normal, except for a bilateral subclonical ankle reflex. The reflexes of Babinski and HoffmannTrömner were bilaterally present. Pseudobulbar reflexes could be elicited, but there was no compulsive laughter or crying. There was a strong grasp reflex of the left hand. She had a left central facial paresis and a moderate palatal insufficiency.

EEG The alpha rhythm was better on the left side. Theta and delta waves were observed around a focus in the left temporoparietal region. (EEGs taken a few months after the accident were dominated by diffuse slow-wave activity.)

Brainstem auditory evoked potentials Normal responses were found with normal interpeak latencies on both sides. Visual evoked potentials In the flash VEP, peaks III-VII could be reliably identified in both hemispheres. Both with the eyes open and closed, all latencies were within normal limits. Pattern VEPs to reversal stimulation $(8 \mathrm{~Hz})$ with high contrast black and white gratings were positive.

CT scan All CSF spaces were diffusely enlarged, both supra- and infratentorially. A hypodense white-matter lesion was seen in the left frontoparietal zone (fig, a). Slices $(3 \mathrm{~mm})$ through the pons and mesencephalon confirmed that the entire brainstem was very thin (fig, b).

Neuro-ophthalmological examinations were performed 5 years 5 months, 5 years 8 months, and 5 years 10 months after the accident. On the first occasion, the patient was able to fixate and to follow moving objects. However, pursuit movements were saccadic. They could only be observed with the patient's head fixed, since otherwise she only made head movements while the eyes remained in the central position. Three months later, eye and head movements could be made independently, and smooth pursuit was possible.

The visual acuity was tested with the preferentiallooking technique ${ }^{11}$ at far and near distances, and found to be stable at 1.5 to $2 \mathrm{~min}$ of arc (normal approximately 0.5-1.0 $\mathrm{min}$ ). Later, the patient was also able to perform letter matching (Sheridan's STYCAR test ${ }^{12}$ ). The acuity for single letters was much poorer than for gratings (5-6 min of arc, normal $1 \mathrm{~min}$ ); the acuity for paired digits was even poorer. The acuity could not be improved by optical
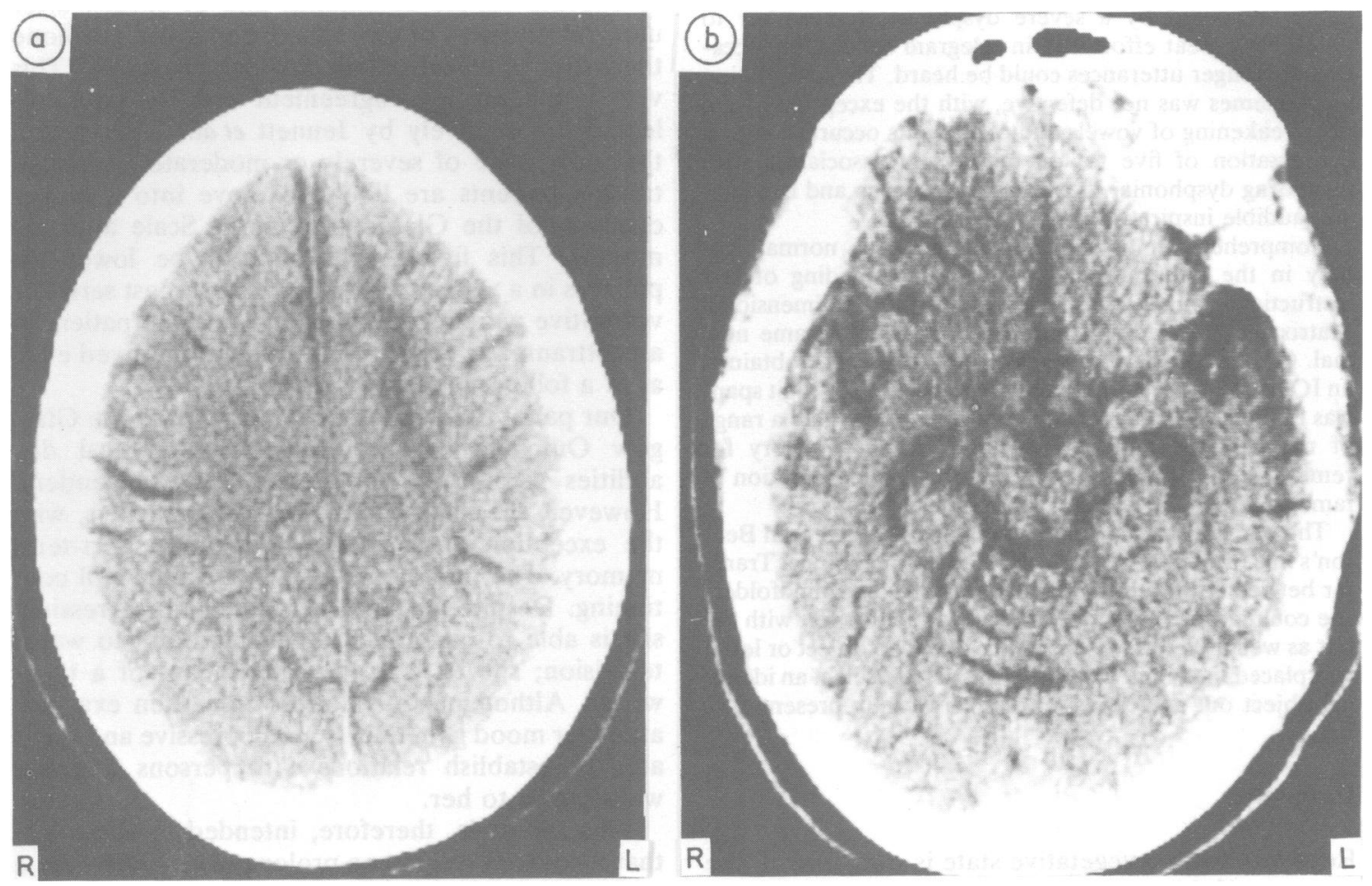

Fig 1 (a) CT scan, made 5 years and 3 months after the accident, shows a linear white-matter hypodensity in the left frontoparietal region. (b) Thin sections of the infratentorial region show gross atrophy of the brainstem and cerebellum. 
Table

\begin{tabular}{|c|c|c|c|c|c|c|}
\hline Authors & $\begin{array}{l}P a \\
\text { sex } \\
(y r\end{array}$ & $\begin{array}{l}\text { and age } \\
\text { ants }\end{array}$ & Aetiology of coma & $\begin{array}{l}\text { First signs of } \\
\text { returning } \\
\text { responsiveness }\end{array}$ & $\begin{array}{l}\text { Duration of } \\
\text { follow-up }\end{array}$ & Residual handicap \\
\hline Higashi et al., 1981" & $\mathbf{F}$ & 61 & SAH & 36 months & 84 months & \multirow{4}{*}{$\begin{array}{l}\text { wheelchair-bound, intellectual } \\
\text { impairment } \\
\text { wheelchair-bound, intellectual } \\
\text { impairment } \\
\text { tetraplegia with limited use of } \\
\text { R hand; R hemianopia; } \\
\text { WAIS IQ 100; unable to read; } \\
\text { impairment of recent memory; } \\
\text { astereognosis } \\
\text { see text for details }\end{array}$} \\
\hline & $\mathbf{M}$ & 26 & anoxia & 8 months & 66 months & \\
\hline Rosenberg et al., $1977^{17}$ & $\mathbf{M}$ & 43 & anoxia & 17 months & 24 months & \\
\hline Present patient & $\mathbf{F}$ & 18 & trauma & 30 months & 72 months & \\
\hline
\end{tabular}

correction. During the first examination, visual field size evaluated with the STYCAR white-ball set $^{12}$ was binocularly normal, but monocularly asymmetrical, with a smaller field for the right than for the left eye. These asymmetries in visual field size disappeared and at the last examination field size was completely normal. The optokinetic nystagmus (OKN) was recorded according to previously published techniques. ${ }^{13}$ Both slow phase and saccades were normal. Binocular OKN was asymmetrical with a preference for clockwise stimulation, probably indicating a leftsided lesion.

Neuropsychological examination on several occasions from five to six years after the accident demonstrated an attentive and co-operative girl. Her verbal expression was badly hampered by a severe dysphonia, forcing her to speak with great effort and in telegram style. Only occasionally longer utterances could be heard. The articulation of phonemes was not defective, with the exception of the ' $L$ '. Weakening of vowels and consonants occurred after a conversation of five to ten minutes in association with increasing dysphonia, short rushes of speech and irregular and audible inspiration.

Comprehension of spoken language was normal, not only in the interview and in the understanding of test instructions, but also as assessed by the Tridimensional Matrix test. ${ }^{14}$ Reading comprehension soon became normal. On the Standard Progressive Matrices ${ }^{15}$ she obtained an IQ of about 75. Her immediate recall (WAIS digit span) was limited (4 digits); retaining information within a range of minutes was minimal. In contrast, her memory for remote events was less severely disturbed (recognition of famous personalities, good topographical memory).

The perception of colours was intact. The score on Benton's line orientation ${ }^{16}$ was within the normal range. Transfer between different modalities was present: blindfolded, she could accurately name objects and letters felt with the left as well as with the right hand. When an object or letter was placed in the left hand, she was able to select an identical object out of a series of objects visually presented to her.

\section{Discussion}

Recovery from a vegetative state is rare, and all the more so, if this state has existed for a long time. In trauma patients, this has to the best of our know- ledge not been described in detail. In the literature, only a few patients are mentioned who recovered from a prolonged vegetative state. The cases with sufficient clinical details provided are summarised in the table..$^{10}$ Only those patients have been included who showed a mental recovery better than merely responding to calling or to simple commands, after a vegetative state of at least six months' duration. In addition to this small group, Bricolo et $a l^{7}$ mention that in their group of 135 patients with prolonged posttraumatic unconsciousness, two patients $\left(1 \frac{1 / 2}{2}\right)$ showed a recovery of the capacity to execute simple commands and of speech after unresponsiveness of six to twelve months, but none thereafter. Clinical details are not provided. ${ }^{7}$ This very low figure is in agreement with the data collected prospectively by Jennett et al. ${ }^{4}$ They found that only $10 \%$ of severely or moderately disabled trauma patients are likely to move into a higher category of the Glasgow Outcome Scale after six months. This figure will probably be lower for patients in a vegetative state. In the largest series of vegetative patients described to date, ${ }^{9}$ no patient in a posttraumatic vegetative state had improved even after a follow-up of five years.

Our patient moved up only one step on the Glasgow Outcome Scale, because her physical disabilities kept her completely ADL-dependent. However, she has regained mental capacities, with the exception of a severely defective short-term memory. The improvement is at the time still continuing. Despite an obvious intellectual regression, she is able to communicate, to read and to watch television; she tries to write by means of a typewriter. Although her emotions are often exaggerated, her mood generally is not depressive and she is able to establish relations with persons who are well-known to her.

This report is, therefore, intended to show: (1) that recovery even after a prolonged vegetative state may occur exceptionally, regardless of its cause; (2) that a considerable improvement of mental func- 
tions from a vegetative state can occur in the context of a progression of only one step, from a vegetative to a severely disabled state, on the Glasgow Outcome Scale.

Thanks are due to Professor R Braakman for helpful comments and to Mrs J Doornbosch-Konijn for secretarial help.

\section{References}

1 Jennett B. Resource allocation for the severely brain damaged. Arch Neurol 1976;33:595-7.

${ }^{2}$ Levy DE, Bates D, Caronna JJ, et al. Prognosis in nontraumatic coma. Ann Int Med 1981;94:293-301.

${ }^{3}$ Jennett B, Teasdale G, Braakman R, Minderhoud J, Knill-Jones RP. Predicting outcome in individual patients after severe head injury. Lancet 1976; 1:1031-4.

${ }^{4}$ Jennett B, Teasdale G, Braakman R, Minderhoud J, Heiden J, Kurze T. Prognosis in series of patients with severe head injury. Neurosurgery 1979;4:283-9.

${ }^{5}$ Gelpke GJ, Braakman R, Habbema JDF, Hilden J. Comparison of outcome in two series of patients with severe head injuries. J Neurosurg 1983;59:745-50.
${ }^{6}$ Higashi K, Sakata Y, Hatano M, et al. Epidemiological studies on patients with a persistent vegetative state. $J$ Neurol Neurosurg Psychiatry 1977;40:876-85.

${ }^{7}$ Bricolo A, Turazzi S, Feriotti G. Prolonged posttraumatic unconsciousness. J Neurosurg 1980;52:625-34.

${ }^{8}$ Margolis LH, Shaywith BA. The outcome of prolonged coma in childhood. Pediatrics 1980;65:477-83.

${ }^{y}$ Higashi K, Hatano M, Abiko S, et al. Five-year followup study of patients with persistent vegetative state. $J$ Neurol Neurosurg Psychiatry 1981;44:552-4.

${ }^{10}$ Rosenberg GA, Johnson SF, Brenner RP. Recovery of cognition after prolonged vegetative state. Ann Neurol 1977;2:167-8.

"Teller DY, Morse R, Borton R, Regal D. Visual acuity for vertical and diagonal gratings in human infants. Vision Res 1974;14:1433-9.

12 Sheridan MD. Manual for the STYCAR Vision Test. Windsor: NFER Publ Co, 1976.

${ }^{13}$ Van Hof-van Duin J, Mohn G. Optokinetic and spontaneous nystagmus in children with neurological disorders. Behave Brain Res 1983;10:163-75.

${ }^{14}$ Kreindler A, Gheorghita N, Voinescu I. Analysis of verbal reception of a complex order with three elements in aphasics. Brain 1971;94:375-86.

15 Raven JC. Progressive Matrices sets I and II. London, HK Lewis, 1959.

${ }^{16}$ Benton AL, Hannay J, Varney NR. Visual perception of line direction in patients with unilateral brain disease. Neurology (Minneap) 1975;25:907-10. 